\title{
Changing Our Image
}

Gwendolyn Levi

$\mathrm{T}$ The ageing of the world's population represents a major success story, while also creating a discrepancy between the image of an older woman and the way they actually feel and act. As society progresses, we are living longer, through new technology and medical research we are delaying the ageing process. Many societies have drastically reduced the incidence of disease, along with the rate of death. Being the fastest growing segment of the population has placed a new emphasis on this age group. The study of ageing has now become a specific discipline called gerontology.

Representing 8.9 per cent of the U.S. population, there are no clearcut definitions for periods of the ageing cycle. Old age had typically been regarded as beginning at 65 , corresponding with the retirement age for workers (WHO, 2013). But today's seniors are fully engaged in life's activities, with many women 65 and older still participating in the workforce. Many are our most prominent and influential people in our communities. A significant number of seniors living today have so much to look forward to: a 'master status', increased affluence and new work practices allow opportunities to explore lifelong interests and more self appreciating goals. Gone are the negative views of being old, of giving up their roles and settling into a state of inactivity; a new area of continued development seems to be sought.

The so-called baby boomers are becoming our next generation of seniors. The designation of being old is becoming more of how one perceives himor herself than actual age. Membership in this group is involuntary, since living allows one to be included. Our perceptions are changing. We now feel more entitled to do what pleases and satisfies us, to slow down and let go of the strain of obligations. Essential things of life gain greater importance. These factors are combining to lessen the trauma of growing old:

- Emphasis on fitness, regular exercise, physical and mental maintenance

- Better medical care, control of disease, reduction in strokes

- Nutrition, wellness programs and a holistic approach to life

- Continued social involvement

Elderly people who stay socially involved tend to be better adjusted overall. Just as young people feel satisfied from achievements, so too do older citizens receive gratification from being useful and productive. 
We are living in comparatively great times for people growing older. In some communities, the increasing demand for services and programs is being met full speed to assist seniors in living full, vital, and dignified lives. Whether they live independently, require assisted living or become residents of long-term facilities, there are many organizations and government programs to ensure that our seniors receive the responsive, respectful assistance in all aspects of their lives. Such programs involve nutrition, wellness, exercise, mental enhancements and referrals to accommodate every need and concern.

Holistic spiritual understanding has also become a way that seniors are pursuing different courses to realize their full potential. By embracing this new attitude and putting into practice positive reinforcement, the assurance of a graceful elderly lifestyle is enhanced (Hart, 2012). Spiritual understanding of life's courses helps the ageing to manoeuver through each life cycle with less adverse outcomes. Having a life of faith, believing and operating in the fullness that this universe has to offer, assures the elderly of the peace of mind necessary to not only survive this life's experiences but to thrive and continue to grow in it.

At Maryland Correctional Institution for Women, the opportunity exists for one to begin a total overview of their individual ageing process in a positive manner. The Women of Wisdom (W.O.W.) is an organization allows prisoners to be in contact with all the components necessary to participate in securing and maintaining a healthy lifestyle, and we invite others to join us in fulfilling our destiny of graceful thriving during this experience.

The W.O.W. organization was established to enrich and enhance the quality of life with emphasis on the senior incarcerated population. This group was created to better ensure that the targeted group (50+ years of age) is prepared to deal with the issues of incarceration and re-entry into society. Our purpose is to provide an avenue for awareness, new initiatives, better resource utilization, and the complete well-being of our senior population through:

- Answering and addressing issues related to wellness, and other topics in the area of women's physical and emotional well-being;

- Connecting with outside resources that share mutual concern (e.g. NWPP, AARP, Department of Aging, Suburban and Johns Hopkins Hospital); and 
- Promoting cooperation and input with existing programs and departments at MCIW, to allow the unique needs of the senior community to be recognized.

Going forward, the Women of Wisdom organization will provide a unique opportunity for its seniors and MCIW to be on the forefront in the newly raised issue of incarcerated seniors. As this population has increased, institutions are coming to realize that the challenges facing them must be met with foresight, planning and the involvement of the incarcerated seniors. Women of Wisdom through its membership of 50+ will ensure that MCIW's older residents are successfully equipped to re-enter society. Through informational seminars, guest speakers, workshops, and other activities, W.O.W. will be trailblazers in recognizing and taking the initiative to deal with the needs of this rapidly growing segment of our prison population.

Ms. Davis (education) is our staff advisor. The National Women's Prison Project (NWPP) with Mrs. Alfrieda Robinson-Dawkins serves as our technical advisor and assists with the program coordination. Thanks to the following for providing additional information and ideas for this article: the Older Women's League (O.W.L.), Our Bodies, Ourselves-Boston Women's Health Collective and Peter Abrahams at Health for Seniors.

To survive this experience and to thrive as a result of living it.

\section{REFERENCES}

CensusScope (2000) Age Distribution. Retrieved from <http://www.censusscope.org/ us/chart_age.html $>$.

Hart, Anne (2012) "Happy people produce less cortisol", San Francisco Examiner - August 11. Retrieved from <http://www.examiner.com/article/happy-peopleproduce-less-cortisol>.

World Health Organization (2013) Health Statistics and Health Information Systems. Retrieved from < http://www.who.int/healthinfo/survey/ageingdefnolder/en/index. html>.

\section{ABOUT THE AUTHOR}

Gwendolyn Levi is incarcerated at the Maryland Correctional Institution for Women. 